\title{
The Lateral Nucleus of the Amygdala Mediates Expression of the Amphetamine-produced Conditioned Place Preference
}

\author{
Noboru Hiroi and Norman M. White \\ Department of Psychology, McGill University, Montreal, Quebec, Canada H3A 1B1
}

We investigated the involvement of the hippocampal formation and the amygdala in the acquisition and expression of the amphetamine-produced conditioned place preference (CPP). Animals were conditioned in four sessions that included two pairings of $d$-amphetamine $(2.0 \mathrm{mg} / \mathrm{kg}, \mathrm{s.c}$.) with one of two distinct compartments and two pairings of vehicle with the other compartment in a counterbalanced manner. Animals' preferences for the compartments were then tested in the absence of amphetamine. The CPP was attenuated by preconditioning electrolytic or excitotoxic lesions of the lateral nucleus of amygdala, but not by electrolytic lesions of the central or basolateral nucleus of amygdala, endopiriform nucleus, or ventral hippocampus or by radio-frequency lesions of the fornix-fimbria. When the lateral nucleus of amygdala was damaged by electrolytic or excitotoxic lesions after conditioning, animals failed to express an amphetamine-produced CPP. These results demonstrate that expression of the amphetamine-produced CPP is mediated by intrinsic neurons of the lateral nucleus of the amygdala, and that neither acquisition nor expression of the CPP is mediated by the central or basolateral amygdaloid nucleus or the hippocampus-accumbens projection. Combined with our previous finding that the expression of the amphetamineproduced CPP is also mediated by dopamine receptor activation in the nucleus accumbens (Hiroi and White, 1989, 1990), it could be suggested that the lateral nucleus of the amygdala and dopamine terminals in the nucleus accumbens are parts of the neural circuitry that mediates the expression of the amphetamine-produced CPP.

The survival of organisms is dependent on behaviors that maximize contact with biologically essential stimuli and minimize contact with noxious and dangerous stimuli. Many of these behaviors are subject to modification through experience. The conditioned place preference (CPP) paradigm is an experimental demonstration of such a modification. In this paradigm, animals increase their contact with an environment in which they have previously encountered biologically essential stimuli. CPPs are

Received Aug. 21, 1990; revised Feb. 1, 1991; accepted Feb. 12, 1991.

This research was supported by grants from the Medical Research Council of Canada and from Fonds pour la Formation de checheurs et l'Aide a la Recherche, Province of.Quebec to N.M.W. N.H. is the recipient of a Government of Canada Award and was supported by a Dalbir Bindra Fellowship from the Faculty of Graduate Studies and Research of McGill University and a Sankei Scholarship from the Sankei Foundation, Japan. We are greatly indebled to Ms. Joanne M. Tilden and Mrs. C. McDonald for their technical assistance.

Correspondence should be addressed to Dr. Noboru Hiroi, Department of Brain and Cognitive Sciences, MIT, E25-618, Cambridge, MA 02139.

Copyright (C) 1991 Society for Neuroscience $0270-6474 / 91 / 112107-10 \$ 03.00 / 0$ established not only by contact with natural stimuli such as food (Spyraki et al., 1982a) and a sexual partner (Agmo and Berenfeld, 1990; Mehrara and Baum, 1990) but also by the effects of injected drugs such as stimulants (Reicher and Holman, 1977; Sherman et al., 1980; Spyraki et al., 1982b; Martin-Iverson et al., 1985; Mithani et al., 1986). Investigation of the neural bases of the drug-induced CPPs is a step toward understanding the modification of behavior through experience by natural incentive stimuli and drugs of abuse.

CPPs are established when dopamine release from the mesolimbic dopamine pathway projecting to the nucleus accumbens is produced by microinjections of amphetamine into nucleus accumbens (Carr and White, 1983, 1986); amphetamine has no effect when injected into other dopamine terminal areas such as striatum, prefrontal cortex, or amygdala (Carr and White, 1986). The establishment of CPPs by systemic amphetamine injections is blocked by systemic injections of dopamine antagonists (Spyraki et al., 1982b; Hiroi and White, 1989) and by 6-hydroxydopamine (6-OHDA) lesions of nucleus accumbens (Spyraki et al., 1982b). We previously reported that the expression of the CPP was blocked by dopamine antagonists injected systemically or into nucleus accumbens before the amphetamine-free test trial (Hiroi and White, 1989, 1990), suggesting that dopamine release in the nucleus accumbens also plays a critical role in the expression of this conditioned behavior. This in turn suggests the role of the mesolimbic dopamine system in some mnemonic process.

Despite the evidence that implicates the mesolimbic dopamine pathway in the acquisition and expression of the CPP, little is known about the involvement of other limbic structures in this type of learning. However, a consideration of the anatomical connections of the nucleus accumbens leads to several obvious possibilities. The nucleus accumbens is a target of massive afferents from the prefrontal (Beckstead, 1979; Phillipson and Griffiths, 1985) and entorhinal (Krayniak et al., 1981; Sorensen and Witter, 1983; Phillipson and Griffiths, 1985) cortices, the subiculum (Swanson and Cowan, 1977; Kelley and Domesick, 1982; Phillipson and Griffiths, 1985), the hippocampus (Raisman ct al., 1966; Siegel et al., 1974; Swanson and Cowan, 1977; Kelley and Domesick, 1982; Phillipson and Griffiths, 1985), and the amygdala (Kelley et al., 1982; Phillipson and Griffiths, 1985). It is noteworthy that two of these structures, the hippocampal system and the amygdala, are involved in memory. Lesions of these structures produce deficits in various memory tasks. Several memory tasks are sensitive to hippocampus or fornix-fimbria lesions, but not to amygdala lesions (Jones and Mishkin, 1972; Parkinson et al., 1988; Zola-Morgan et al., 1989; Peinado-Manzano, 1990; Sutherland and McDonald, 1990). Others are sensitive to amygdala, but not to 
hippocampal lesions (Jones and Mishkin, 1972; Spiegler and Mishkin, 1981; Murray and Mishkin, 1985; Peinado-Manzano, 1990).

The present study was designed to investigate the involvement of the hippocampal system and the amygdala in the acquisition and expression of the amphetamine-produced CPP. Because the hippocampus and subiculum project to the nucleus accumbens through the fornix-fimbria (Raisman et al., 1966; Swanson and Cowan, 1977; Kelley and Domesick, 1982; Totterdell and Smith, 1989), lesions were made to this fiber bundle. The other structure studied, the amygdala, is made up of heterogeneous nuclei. Most workers have used lesions to the basolateral complex and its adjacent areas in rats (Cador et al., 1989; Everitt et al., 1989; Sutherland and McDonald, 1990) and gross amygdalectomy in monkeys (Jones and Mishkin, 1972; Murray and Mishkin, 1985; Parkinson et al., 1988; Zola-Morgan et al., 1989). Because these nuclci have different projections (de Olmos et al., 1985), we made small electrolytic lesions confined to either central, basolateral, or lateral nucleus of amygdala. Because these nuclei are surrounded by fibers of passage that are functionally unrelated to them, we also made lesions using the excitotoxin NMDA, which destroys intrinsic neurons, but not fibers of passage (Mayer and Westbrook, 1987). We also made electrolytic lesions in two additional areas, the endopiriform nucleus and ventral hippocampus, which were damaged by NMDA lesions of the lateral nucleus of amygdala.

The present study was previously presented in a preliminary form (Hiroi et al., 1990).

\section{Materials and Methods}

Subjects. The subjects were 108 experimentally naive male Long-Evans rats purchased from Charles River Canada, St. Constant, Quebec, weighing from 275 to $375 \mathrm{gm}$ at the start of the experiments. The animals were individually housed in single cages with food and water available ad libitum.

Apparatus. The CPP apparatus was made of wood, with a Plexiglas front wall. It consisted of three different compartments, two of which were identical in size $(45 \times 45 \times 30 \mathrm{~cm})$. These two compartments differed in visual, tactile, and olfactory cues. One compartment was painted white and had wood chips with a mild smell on a smooth floor. The other compartment was painted black with white vertical stripes. The floor of the latter compartment was made of $12-\mathrm{mm}$ wire mesh. A few drops of vinegar $(1 \mathrm{ml} 2 \%$ acetic acid) were placed on the floor of this compartment below the wire mesh. These two compartments were completely separated from each other by a wooden partition. An entrance to each compartment was located at the rear next to the partition. An unpainted tunnel $(36 \times 18 \times 20 \mathrm{~cm})$, protruding from the rear of the two large compartments, connected the two entrances. This apparatus does not induce any unconditional preference for either compartment on a group basis (Carr and White, 1983; Clarke et al., 1990).

Nichrome electrodes $(0.25 \mathrm{~mm}$ in diameter) with enamel insulation were used for electrolytic and radio-frequency lesions. The tips $(0.8$ $\mathrm{mm}$ ) of the electrodes were decoated with Strip X (GC Electronics).

Cannulas used for NMDA injections were made from 30-ga hypodermic needles. The cannulas were attached to a 5.0- $\mu$ l Hamilton syringe with PE 10 tubing.

Procedure. The CPP procedure required six sessions with one session per day. On session 1, all three compartments of the apparatus were open. The rats were placed into the tunnel and allowed to move freely in the three compartments for $10 \mathrm{~min}$. The next four sessions included two pairings with $d$-amphetamine and two pairings with saline. Rats in each treatment group were randomly assigned to the cells of a $2 \times 2$ factorial design. One factor was pairing compartment (black or white), and the other was injection order. Half of the rats in each group received subcutaneous injections of $d$-amphetamine $(2.0 \mathrm{mg} / \mathrm{kg}$, dissolved in 1.0 $\mathrm{ml} / \mathrm{kg}$ physiological saline) before exposure to the white compartment, and the other half received the $d$-amphetamine injections before exposure to the black compartment. Within each of these subgroups, half of the rats received $d$-amphetamine injections on even-numbered sessions and vehicle injections on odd-numbered sessions; the pattern was reversed for the remaining rats. The animals were placed into the appropriate compartment immediately after receiving their injections and were left there for $30 \mathrm{~min}$. The entrances to the compartments were blocked, so that the animals were confined to the compartments.

The sixth session was a test session. No $d$-amphetamine or saline was injected. The entrances to the compartments were open. The animals were placed into the tunnel and allowed to move freely in the three compartments for $20 \mathrm{~min}$. The amount of time spent in each of the two large compartments was recorded by observers who were not aware of the treatments the animals had received.

Surgery and histology. Lesions were made either before or after conditioning. Rats in the preconditioning lesion groups were operated 1 week before the CPP procedure began. The animals received no treatment, electrolytic lesions of the lateral, central, basolateral, or endopiriform nucleus or ventral hippocampus, or radiofrequency lesions of fornix-fimbria. Another two groups received NMDA or sham lesions of the lateral amygdaloid nucleus. Rats in the postconditioning lesion groups were operated $24 \mathrm{hr}$ after the last conditioning session and tested after a 1 -week recovery period. Two groups received electrolytic or sham lesions of the lateral nucleus of the amygdala, and another two groups received NMDA or sham lesions of the lateral nucleus of the amygdala.

To produce the lesions, the rats were anesthetized with $65 \mathrm{mg} / \mathrm{kg}$ of sodium pentobarbital and subjected to standard stereotaxic surgery using coordinates based on the atlas of Paxinos and Watson (1982). The three amygdaloid nuclei and their two adjacent structures were each damaged electrolytically. Groups, each consisting of eight rats, received no treatment or electrolytic lesions of the lateral (anterior, -3.5 ; latcral, \pm 5.5 ; ventral, $-8.5 \mathrm{~mm}$ ), central (anterior, -2.3 ; lateral, \pm 4.5 ; ventral, $-8.5 \mathrm{~mm}$ ), or basolateral (anterior, -2.8 ; lateral, \pm 5.0 ; ventral, -9.0 $\mathrm{mm}$ ) nucleus of amygdala, endopiriform nucleus (anterior, -4.3 ; lateral, \pm 6.0 ; ventral, $-8.5 \mathrm{~mm}$ ), or ventral hippocampus (anterior, -4.8 ; lateral, \pm 5.5 ; ventral, $-8.0 \mathrm{~mm}$ ). The lesion parameters were $1.5 \mathrm{~mA}$ for $20 \mathrm{sec}$.

Pilot studies revealed that radio-frequency lesions produced more complete damage to fornix-fimbria than electrolytic lesions. Therefore, the fornix-fimbria (anterior, -1.5 ; lateral, \pm 1.0 and \pm 2.2 ; ventral, -4.5 $\mathrm{mm}$ ) was damaged by radio-frequency lesions. The parameters were 6 $\mathrm{mA}$ for $40 \mathrm{sec}$.

Four groups, each consisting of 8-12 rats, received bilateral injections of NMDA $(0.25 \mathrm{~m}$ in phosphate buffer, $\mathrm{pH} 7.0)$ or vehicle into the lateral nucleus of amygdala. Cannulas loaded with either NMDA or phosphate buffer were lowered to the lateral nucleus (anterior, -3.5 ; lateral, \pm 5.5 ; ventral, $-8.0 \mathrm{~mm})$. The solutions $(0.3 \mu \mathrm{l})$ were infused over a 330 -sec period by a Harvard minipump, and the cannulas were left in position for a further $120 \mathrm{sec}$. After surgery, the lesioned animals were monitored. When early signs of epileptic seizure were noted, additional injections of sodium pentobarbital $(3.25 \mathrm{mg})$ were given.

After completion of behavioral testing, the animals were killed with an overdose of chloral hydrate, and their brains were removed, fixed in formol saline, sectioned, and stained with Luxol fast blue and neutral red.

\section{Results}

Histology

Figure $1 A$ shows the extent of each of the six preconditioning lesions. Electrolytic lesions aimed at the lateral nucleus of amygdala produced damage to the middle and posterior parts of this nucleus in all cases (Fig. $1 \mathrm{~A}$ ). In a few cases, the lesions extended into the endopiriform nucleus. Lesions aimed at the central amygdaloid nucleus were well confined to this structure in all cases. Lesions aimed at the basolateral amygdaloid nucleus mostly damaged the middle and posterior parts of this nucleus and the basomedial nucleus. These lesions did not extend into the lateral nucleus of amygdala. Lesions of the endopiriform nucleus damaged posterior parts of the nucleus, which are located posterolaterally to the lateral nucleus of the amygdala. The lesions did not extend to the lateral amygdaloid nucleus or the basolateral nucleus of amygdala. Lesions aimed at the ventral hippocampus, which is located posteromedially to the lateral 

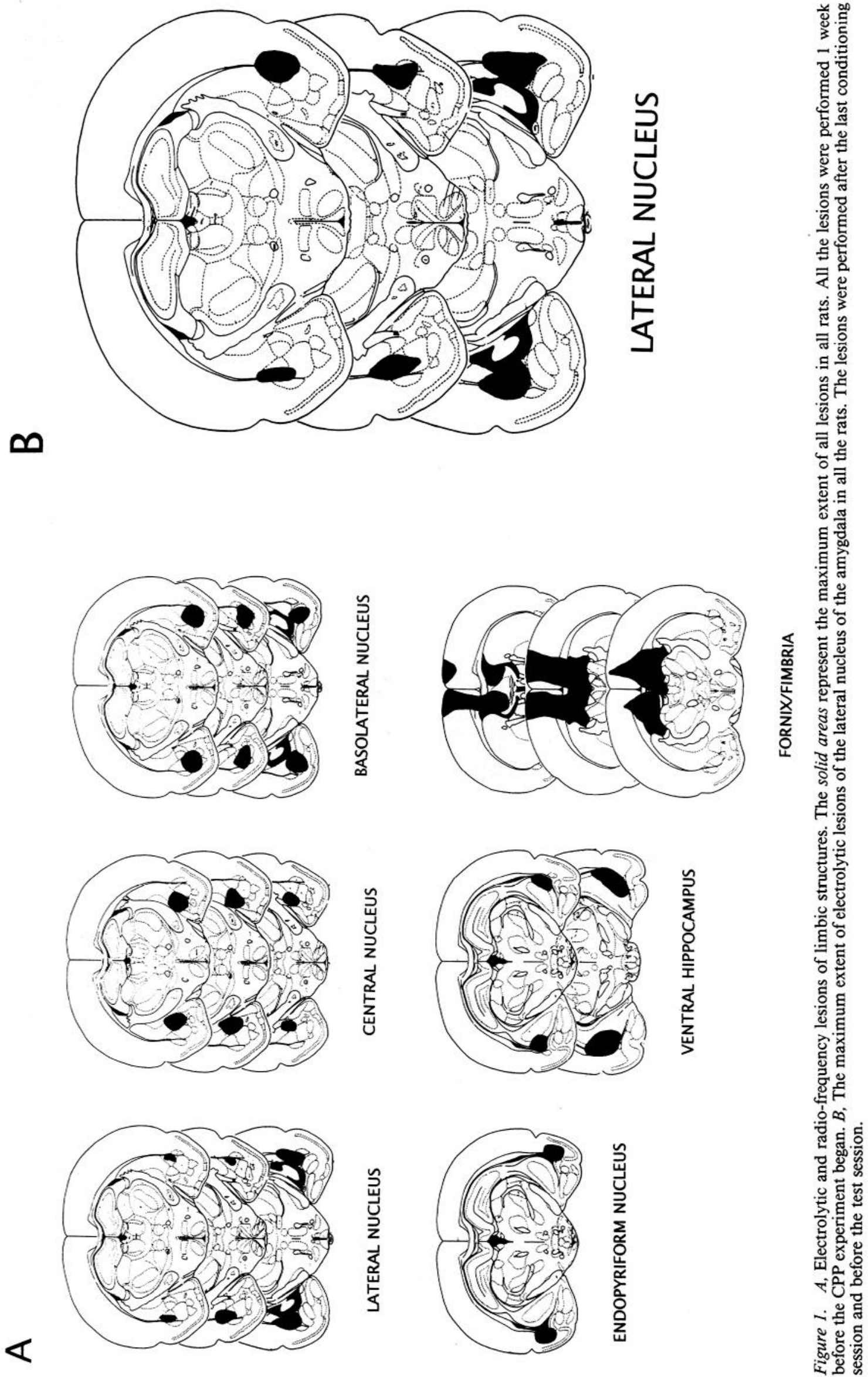

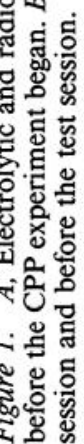


A

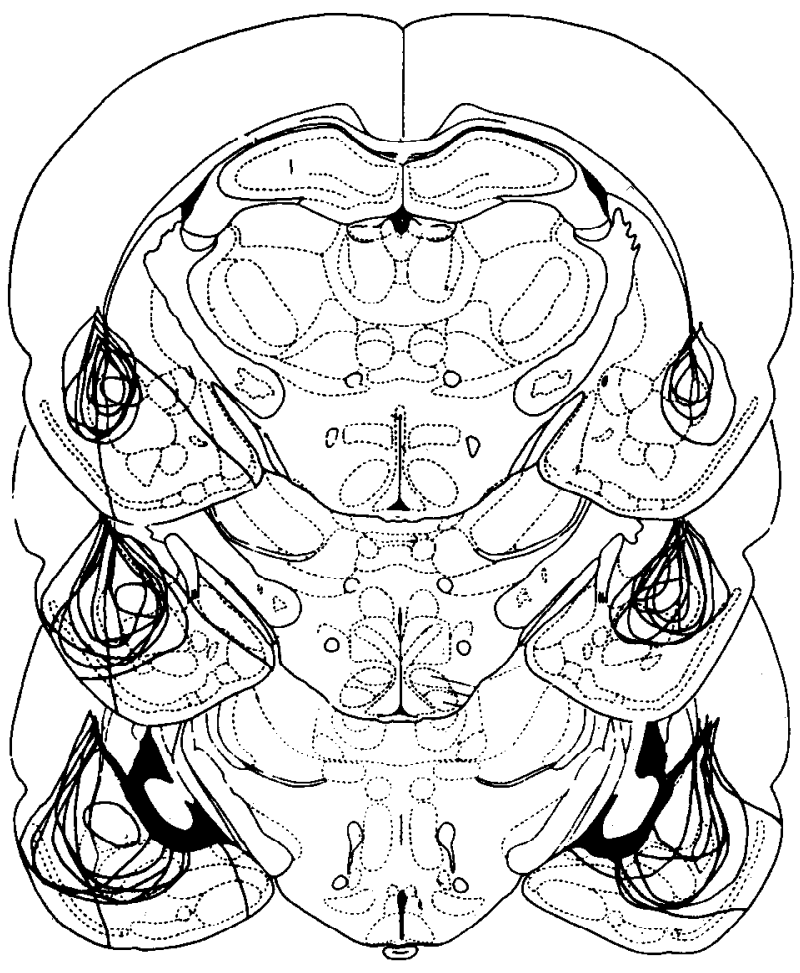

B

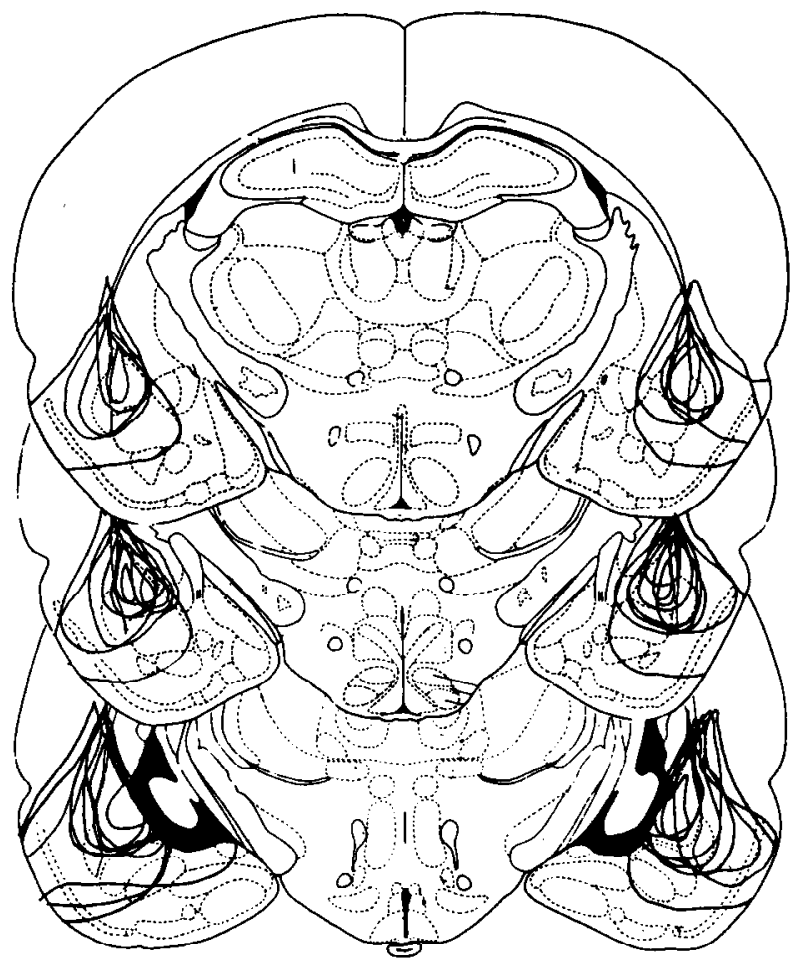

Figure 2. $A$, NMDA lesions of the lateral nucleus of amygdala. The lesions were performed 1 week before the conditioning sessions. $B$, The extent of postconditioning NMDA lesions of the lateral nucleus of amygdala. The lesions were performed after the last conditioning session and before the test session. $C$, Representative brain sections showing the extent of NMDA lesions of the lateral nucleus of amygdala. The arrowheads delineate the affected areas that showed cell loss and extensive gliosis. 1 , control; 2 , large lesion; 3 and 4 , small lesions. 1-3 were from the preconditioning lesion groups, and 4 was from the postconditioning lesion group.

amygdaloid nucleus, produced damage in ventrolateral parts of the structure. Radio-frequency lesions of the fornix-fimbria produced substantial damage to the target. The cortex and cingulum were also damaged in some of the cases.

Postconditioning electrolytic lesions of the lateral nucleus of amygdala produced lesions comparable to those in the preconditioning group (Fig. 1B). The middle and posterior parts of the nucleus were substantially damaged.

Figure 2, $A$ and $B$, shows the extent of NMDA lesions aimed at the lateral nucleus of amygdala. In both pre- and postconditioning lesions, there was substantial neuronal cell damage in the lateral nucleus in all cases. Most rats also had substantial damage to the basolateral nucleus. In some of these cases, the lesions extended to the basomedial nucleus bilaterally or unilaterally. In all cases, the endopiriform nucleus was damaged. A few rats had partial damage to the central nucleus. The dorsolateral part of the primary olfactory cortex was damaged in a few rats. In all cases, the lesions also damaged a part of the hippocampus located posteromedially to the lateral nucleus across the lateral ventricle. This damaged area corresponded to the part of the ventral hippocampus damaged by electrolytic lesions (Fig. 1A).

Representative photomicrographs are shown in Figure $2 C$. The control brain (Fig. 2C1) shows well-delineated lateral, basolateral, and endopiriform nuclei in the posterior amygdala, which are surrounded by a layer of cell bodies of the primary olfactory cortex. The lesioned areas (Figs. $2 \mathrm{C2}-4$ ) are characterized by neuronal cell loss shown as pale areas and extensive gliosis shown as intensely dark areas. Due to these changes, distinctions among nuclei are blurred. In the case of a large lesion (Fig. 2C2), the damaged area covered the lateral and basolateral amygdaloid nuclei, endopiriform nucleus, a part of the primary olfactory cortex, and the posterolateral cortical amygdaloid nucleus. Small lesions (Figs. 2C3,4) damaged the lateral nucleus of amygdala substantially and its adjacent nuclei slightly.

In summary, the electrolytic lesions were well confined to each target area of amygdala. NMDA lesions produced cell damage affecting the lateral, central, basolateral, basomedial, and endopiriform nuclei and ventral hippocampus. Thus, these two lesion techniques achieved complementary effects. Electrolytic lesions achieved good regional localization, and NMDA lesions damaged neuronal cell bodies, but not fibers of passage.

\section{Effects of preconditioning lesions of limbic structures}

Figure $3 A$ shows the effects of preconditioning electrolytic or radio-frequency lesions on the amphetamine CPP. A two-way ANOVA with planned comparisons, with groups as one factor and compartments as the other (repeated measure) revealed significant differences between the amount of time spent in the paired and unpaired compartments for the control $[F(1,49)=$ $11.8 ; p<0.01]$, central nucleus $[F(1,49)=5.6 ; p<0.05]$, basolateral nucleus $[F(1,49)=15.7 ; p<0.01]$, endopiriform nucleus $[F(1,49)=14.4 ; p<0.01]$, ventral hippocampus $[F(1,49)$ $=4.7 ; p<0.05]$, and fornix-fimbria $[F(1,49)=7.5 ; p<0.01]$ groups. There was no significant difference in time spent in the 

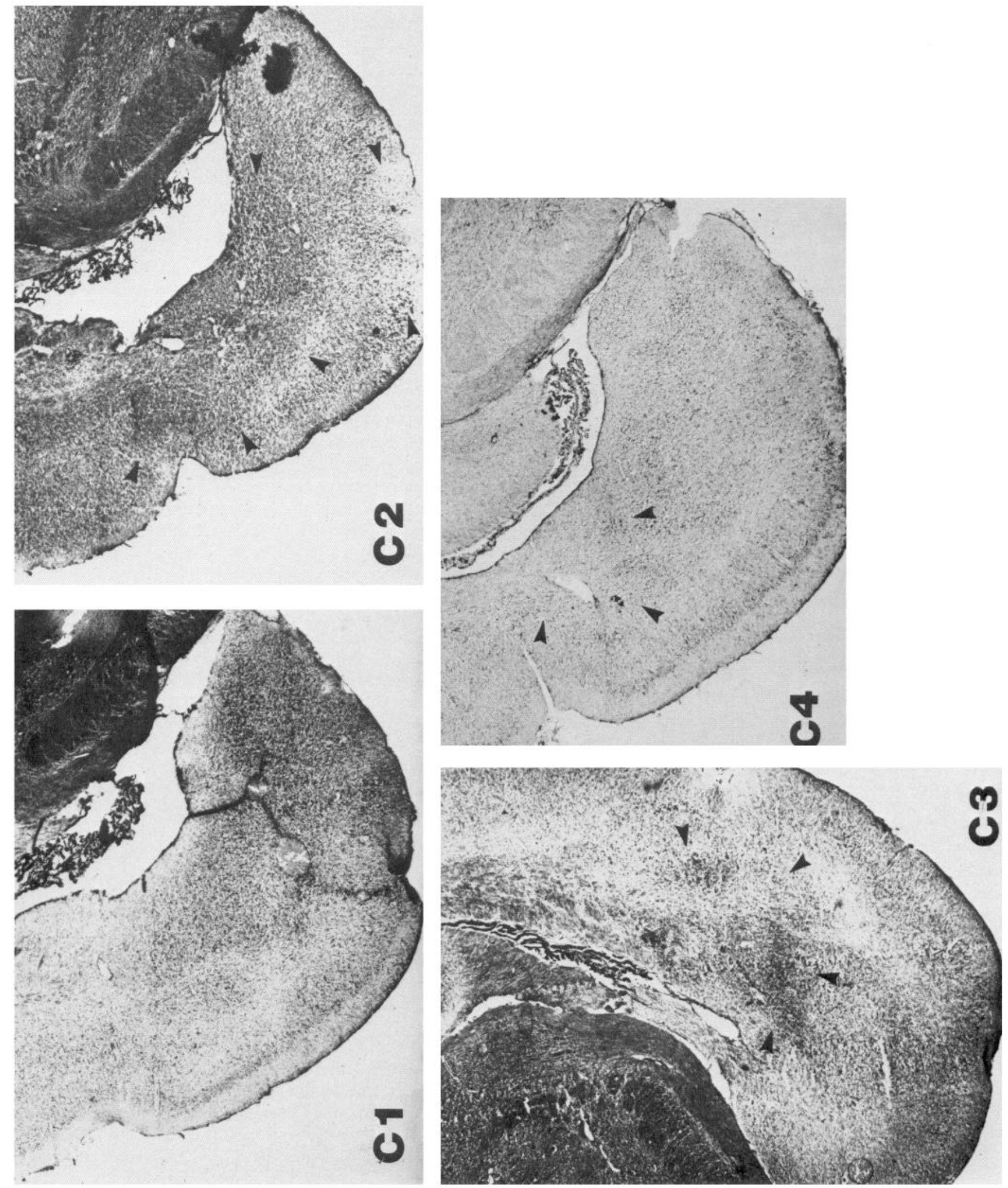


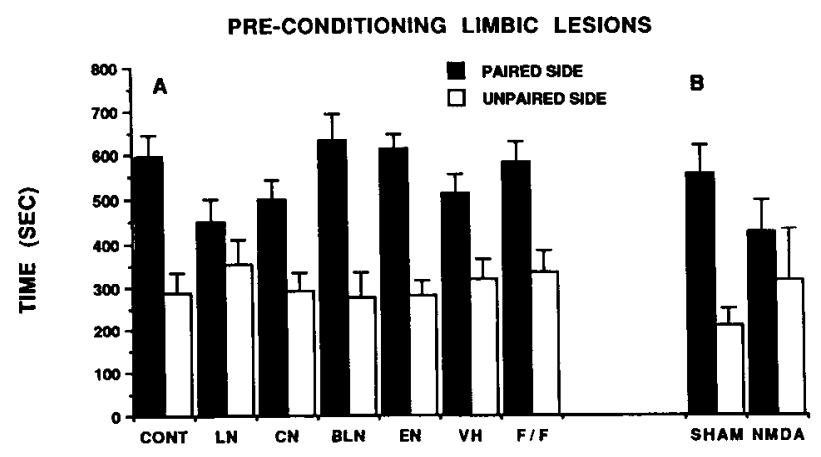

Figure 3. A, Effects of lesions of the limbic structures on the amphetamine-produced CPP. All the electrolytic and radio-frequency lesions were performed 1 week before the conditioned sessions began. CONT, control; $L N$, lateral nucleus; $C N$, central nucleus; $B L N$, basolateral nucleus; $E N$, endopiriform nucleus; $V H$, ventral hippocampus; $F / F$, fornix-fimbria. $B$, Effect of NMDA lesions of the lateral nucleus of amygdala on the amphetamine CPP. NMDA lesions were performed before the conditioning sessions. $S H A M$, vehicle-infused group; $N M D A$, NMDA-infused group. Paired side, amphetamine-paired compartment; unpaired side, saline-paired compartment. The vertical lines on the bars indicate +SEM.

two compartments for the lateral nucleus group $[F(1,49)=1.3$; $p>0.05]$. The mean difference in time spent in the two large compartments by the animals in the control group was significantly different from that for the lateral nucleus group $[F(1,98)$ $=19.0 ; p<0.01]$, but not from those for the central amygdaloid $[F(1,98)=2.1 ; p>0.05]$, basolateral amygdaloid $[F(1,98)=$ $0.51 ; p>0.05]$, or endopiriform $[F(1,98)=0.23 ; p>0.05]$ nuclei, ventral hippocampus $[F(1,98)=2.9 ; p>0.05]$, or fornixfimbria $[F(1,98)=0.87 ; p>0.05]$ groups. The mean difference in time spent in the two large compartments for the lateral nucleus group was significantly different from that for the basolateral nucleus group $[F(1,98)=14.4 ; p<0.01]$, endopiriform nucleus group $[F(1,98)=12.7 ; p<0.01]$, and fornix-fimbria group $[F(1,98)=4.6 ; p<0.05]$, but not for the central nucleus group $[F(1,98)=2.7 ; p>0.05]$ or ventral hippocampus group $[F(1,98)=1.9 ; p>0.05]$. The animals in the lateral nucleus group spent an average of $38 \%, 29 \%$, and $33 \%$ of the total test time in the paired, unpaired, and tunnel compartments, respectively; for the control group these values were $50 \%, 24 \%$, and $26 \%$.

Figure $3 B$ shows the effect of preconditioning NMDA lesions of the lateral nucleus of amygdala on the amphetamine CPP. Planned comparisons revealed that the difference between the time spent in the two large compartments was significant for the control group $[F(1,14)=5.7 ; p<0.05]$, but not for the group with the NMDA lesions $[F(1,14)=0.54 ; p>0.05]$. The mean difference in time spent in the two large compartments by the animals in the control group was significantly different from that for the NMDA-lesioned group $[F(1,28)=9.3 ; p<$ 0.01 ]. The animals in the control group spent an average of $46 \%$, $17 \%$, and $37 \%$ of the total test time in the paired, unpaired, and tunnel compartments, respectively; for the NMDA-lesioned group these values were $35 \%, 26 \%$, and $38 \%$.

\section{Effects of postconditioning lesions to the lateral nucleus of amygdala}

Electrolytic lesions of the lateral nucleus attenuated expression of the CPP (Fig. 4A). Planncd comparisons showed that there was a significant difference between time spent in the two large
POST-CONDITIONING LESIONS OF THE LATERAL NUCLEUS

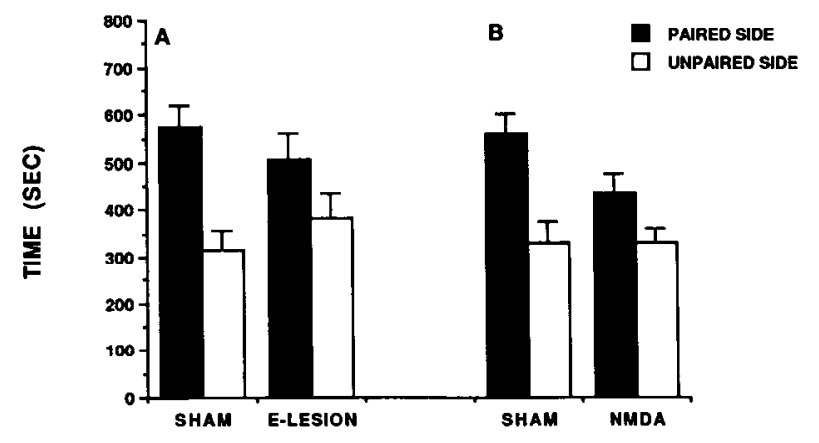

Figure 4. Effects of postconditioning electrolytic $(A)$ and NMDA $(B)$ lesions of the lateral nucleus of amygdala on the expression of the amphetamine-produced CPP. The lesions were performed after the last conditioning session and before the test session. $A, S H A M$, sham-operated group; $E-L E S I O N$, electrolytic lesion group. $B, S H A M$, vehicleinfused group; NMDA, NMDA-infused group. Paired side, amphetamine-paired compartment; unpaired side, saline-paired compartment. The vertical lines on the bars indicate +SEM.

compartments for the sham group $[F(1,14)=7.5 ; p<0.05]$, but not for the lesioned group $[F(1,14)=1.7 ; p>0.05]$. The mean difference in time spent in the two large compartments by the animals in the control group was significantly different from that for the lesioned group $[F(1,28)=7.5 ; p<0.05]$. The animals in the control group spent an average of $48 \%, 26 \%$, and $26 \%$ of the total test time in the paired, unpaired, and tunnel compartments, respectively. For the NMDA-lesioned group, these values were $42 \%, 32 \%$, and $26 \%$.

The NMDA lesions also attenuated expression of the CPP (Fig. 4B). Planned comparisons revealed a significant difference between time spent in the amphetamine-paired and unpaired compartments for the control $[F(1,19)=10.6 ; p<0.01]$, but not for the NMDA-lesioned group $[F(1,19)=1.8 ; p>0.05]$. The mean difference in time spent in the two large compartments by the animals in the control group was significantly different from that for the NMDA-lesioned group $[F(1,38)=$ $8.4 ; p<0.01]$. The animals in the control group spent an average of $47 \%, 28 \%$, and $26 \%$ of the total test time in the paired, unpaired, and tunnel compartments, respectively. For the NMDA-lesioned group, these values were $36 \%, 28 \%$, and $36 \%$.

\section{Discussion}

The present study shows that the amphetamine CPP was attenuated by preconditioning electrolytic or NMDA lesions of the lateral nucleus of amygdala, but not by electrolytic lesions of its adjacent areas or by radio-frequency lesions of fornix-fimbria. The fact that the time difference for the lateral nucleus group was not significantly different from that for the central nucleus or ventral hippocampus group is difficult to interpret. The facts that (1) the rats in both the central nucleus and the ventral hippocampus groups spent significantly more time in the paired compartment than in the unpaired compartment and (2) their time differences were not different from that of the control group make it clear that these lesions did not impair the CPP. On the other hand, it is also clear that lateral nucleus lesions did not completely eliminate the CPP in any of the experiments described here, and this issue is considered in a later part of this Discussion. It seems likely that the failure of lateral nucleus lesions to abolish the CPP completely is the basis 
of lack of the significant difference between the lateral nucleus group and some of the other groups.

When the lateral nucleus of amygdala was damaged by electrolytic or NMDA lesions after conditioning, animals also failed to express amphetamine CPPs. Although NMDA lesions aimed at the lateral nucleus of amygdala also affected the central, basolateral, and basomedial amygdaloid nuclei, endopiriform nucleus, and ventral hippocampus, electrolytic lesions confined to each of these five structures produced no impairments. These results show that intrinsic neurons of the lateral nucleus of the amygdala mediate the expression of the amphetamine-produced CPP and that the central, basolateral, and basomedial amygdaloid nuclei, the endopiriform nucleus, and the hippocampal system are probably not involved in mediating acquisition or expression of this type of learning.

Because amygdala lesions are known to affect behaviors normally exhibited in the presence of novel stimuli (Rolls and Rolls, 1973; Nachman and Ashe, 1974; Peinado-Manzano, 1988), the possibility that the CPP measures responses to novelty that were eliminated by lesions of the lateral nucleus must be considered. If, by some unknown mechanism, amphetamine acted to preserve the novelty of the stimuli in the paired compartment, the drug might produce a preference for this compartment over the unpaired compartment (Scoles and Siegel, 1986), simply because rats tend to explore novel stimuli (Bardo et al., 1989). However, because amygdala lesions potentiate this tendency to explore novel stimuli (Rolls and Rolls, 1973; Nachman and Ashe, 1974; Peinado-Manzano, 1988) and the effect of the lesions in the present study was a reduction in preference, this cannot be the explanation of the observed effects. The suggestion that an increased tendency to explore novel stimuli cannot explain the absence of a CPP is further strengthened by the finding that, on the test day, the control and lateral nucleus-lesioned groups spent comparable times in the tunnel, to which the animals had been exposed only once. The proportion of time spent in the tunnel ranged between $26 \%$ and $37 \%$ for the controls and between $26 \%$ and $38 \%$ for the lesioned groups.

An alternative possibility is that amphetamine, again by some unknown mechanism, might increase the familiarity of the stimuli in the paired compartment (Swerdlow and Koob, 1984), leading the animals to avoid the unpaired compartment because of neophobia for the relatively less familiar stimuli in that compartment. However, the fact that the animals had experienced three sessions of exposure to the unpaired compartment before the test trial makes it highly unlikely that the level of novelty represented by these stimuli would be high enough to induce neophobia. In fact, as conditioning progressed, animals often lay on the floor of the unpaired compartment, exhibiting no neophobic responses whatever, suggesting that animals did not perceive the unpaired compartment as novel. Therefore, it seems very unlikely that the effects of amygdala lesions on neophobic responding can explain the findings of the present experiments.

\section{The mnemonic requirement of the amphetamine CPP}

Previous studies have shown that hippocampus or fornix-fimbria lesions (Jones and Mishkin, 1972; Parkinson et al., 1988; Zola-Morgan et al., 1989; Peinado-Manzano, 1990; Sutherland and McDonald, 1990) and amygdala lesions (Jones and Mishkin, 1972; Spiegler and Mishkin, 1981; Murray and Mishkin, 1985; Peinado-Manzano, 1990) produce complementary deficits in several tasks. These tasks could be categorized as hippocampus-type and amygdala-type memory tasks, solely based upon the empirical evidence of their differential sensitivity to lesions of the two areas.

In the present study, complete lesions of the fornix-fimbria had no effect on the amphetamine CPP, suggesting that the CPP is not representative of the type of memory mediated in the hippocampus. Considering the fact that performance of memory tasks that tax place learning is impaired by lesions of the fornixfimbria or hippocampus (Jones and Mishkin, 1972; Parkinson et al., 1988; Zola-Morgan et al., 1989; Sutherland and McDonald, 1990), it seems likely that the present CPP paradigm does not involve "place" learning. If more diffuse spatial cues were used, however, the CPP might be impaired by hippocampus or fornix-fimbria lesions.

Monkeys with amygdala lesions, but not hippocampal lesions, show poor performance on object discrimination reversal (Jones and Mishkin, 1972) and trial-unique object discrimination (Spiegler and Mishkin, 1981) tasks. Amygdala lesions also produce impairments in discrimination learning in rats (PeinadoManzano, 1987, 1988, 1989, 1990). These deficits are generally interpreted as suggesting that the amygdala is involved in stimulus-reward associations. These discrimination paradigms involve complex and redundant behavioral contingencies. In them, animals face a pair of stimuli, response to one of which is followed by presentation of a primary rewarding stimulus. The tasks would involve all the possible associative linkages proposed by Estes (1969): stimulus-reward, stimulus-response, and response-reward associations. Furthermore, some of the tasks also involve reversal learning and rule learning. Thus, the impairments observed in these tasks cannot be interpreted in terms of a single process.

The mnemonic requirement of the CPP paradigm seems to be simpler than that of discrimination learning, because it involves pairings of neutral stimuli and primary rewarding effects independently of animals' responses. Operationally, this experimental situation seems to be equivalent to the one described by Gaffan et al. (1988). In that study, presentation of a stimulus was followed by food, while presentation of another stimulus was not, regardless of the animals' responses. When given a choice after these pairings, the animals chose the stimulus that had been paired with food. Disconnection of the amygdala from the inferotemporal cortex eliminated this behavior. The results of Gaffan et al. (1988) and those of the present study provide evidence that the amygdala mediates stimulus-reward learning, and the present results further show that intrinsic neurons of the lateral nucleus of the amygdala are involved in this type of association, at least in rats.

\section{Acquisition of the stimulus-reward association in the amphetamine CPP}

Because preconditioning lesions of the central and basolateral amygdaloid nuclei had no effect on the amphetamine-produced CPP, it seems unlikely that these nuclei are involved in the acquisition of stimulus-reward associations. The finding that preconditioning lesions of the lateral nucleus attenuated the amphetamine-produced CPP does not provide clear evidence that this nucleus is involved in the acquisition of stimulusreward associations, because preconditioning lesions affect both acquisition and expression, and postconditioning lesions, which affect expression only, produced impairment. Nonetheless, the data are consistent with the notion that the amygdala is involved in acquisition of stimulus-reward associations (Jones and Mishkin, 1972; Spiegler and Mishkin, 1981; Gaffan et al., 1988). 
An acquisition deficit could be due to an impairment of perception of the neutral sensory stimuli, impairment of the primary rewarding effect of amphetamine, and/or impairment of the associative interaction between the two. The first possibility is unlikely because amygdala-lesioned animals clearly locate environmental stimuli and objects (Kluver and Bucy, 1937, 1939; Schreiner and Kling, 1953, 1956) and show normal visual acuity (Kluver and Bucy, 1937, 1939).

The second possibility is also unlikely. In the present study, the primary rewarding effects were produced by amphetamine, which establishes CPPs by inducing dopamine release (Spyraki et al., 1982b; Hiroi and White, 1989). Dopamine terminals in the amygdala are distributed primarily in the central nucleus (Ben-Ari et al., 1975). Microinjections of amphetamine into the central nucleus do not establish CPPs (Carr and White, 1986). Rather, dopamine terminals in the nucleus accumbens seem to be the critical site of action of amphetamine, because 6-OHDA lesions of nucleus accumbens attenuate the CPP induced by systemic injections of amphetamine (Spyraki et al., 1982b) and microinjections of amphetamine into nucleus accumbens establish CPPs (Carr and White, 1983, 1986). Although this does not entirely exclude the possibility that amphetamine acts on dopamine terminals in the amygdala to establish the CPP, it is unlikely that amphetamine produces its primary rewarding effects in the amygdala. This implies that the deficit observed in the present study is probably not due to impaired primary rewarding effects of amphetamine.

The remaining explanation for the effect of lateral amygdaloid nucleus lesions observed in the present study is that they disrupted the associative interaction between neutral stimuli and the primary rewarding effect of the drug. If the site of action of amphetamine's primary rewarding effect is dopamine terminals in the nucleus accumbens, some form of interaction between the dopamine system and the lateral nucleus of the amygdala is implied. Such an interaction might involve the flow of a reward signal from the nucleus accumbens to the amygdala. There are anatomical projections from the nucleus accumbens to the ventromedial part of globus pallidus (ventral pallidum of Heimer and Wilson, 1975) (Swanson and Cowan, 1975; Williams et al., 1977; Nauta et al., 1978). The latter area gives rise to projections to the lateral nucleus of the amygdala (Ottersen, 1980, 1981; Groenewegen and Van Dijk, 1984). The lateral nucleus of the amygdala of the rat also receives visual, auditory, somatosensory, and taste inputs from primary sensory cortical areas via the periallocortex (Turner, 1981; Turner and Zimmer, 1984 ) and olfactory inputs from the olfactory bulb via the piriform cortex (de Olmos et al., 1985; Switzer et al., 1985). Thus, the lateral nucleus could be viewed as a site of convergence of sensory stimuli and primary rewarding effects, which seems to provide a suitable basis for the establishment of stimulus-reward associations. The confluence of these two types of signals in the lateral nucleus of the amygdala might be a necessary event for the association between them to be formed.

\section{Expression of the stimulus-reward association in the amphetamine-produced CPP}

Because electrolytic and NMDA lesions of the lateral nucleus made after the conditioning sessions attenuated the expression of the amphetamine-produced CPP, the present results provide evidence that the expression of behavior guided by conditioned stimuli is mediated by intrinsic neurons of the lateral nucleus of the amygdala. Although amygdala lesions generally have not produced deficits on preoperationally acquired discriminations (Hearst and Pribram, 1964; Peinado-Manzano and MartinezMartin, 1987; Peinado-Manzano, 1988; Cador et al., 1989), this might be due to the fact that the discrimination tasks uscd in these studies had more than one mnemonic solution. In fact, when the importance of a stimulus-reward association is maximized in a task, considerable impairment has been observed (Everitt et al., 1989; present results). In Everitt's study, extensive excitotoxic lesions were made including the basolateral nucleus and a part of the lateral nucleus, central nucleus, and other adjacent areas. The present results indicate that it is the lateral nucleus, but not the other amygdaloid nuclei, that mediates retrieval and/or storage of stimulus-reward associations.

We previously reported that a dopamine antagonist injected into nucleus accumbens abolished the expression of the amphetamine CPP (Hiroi and White, 1990), suggesting that dopamine release in the nucleus accumbens is another important neural event for expressing previously acquired stimulus-reward associations. Together with the present results, it might be suggested that dopamine terminals in the nucleus accumbens and the lateral nucleus of the amygdala are parts of the circuitry that mediates expression of the process through which these associations influence behavior. The process might involve the projection of the lateral nucleus of the amygdala to the nucleus accumbens (Kelley et al., 1982; Phillipson and Griffiths, 1985).

It should be noted that in no case was a complete blockade of the CPP observed, even though groups of animals with lateral nucleus lesions did not show statistically significant CPPs. One explanation could be the redundancy of brain functions. In the presence of amygdala lesions, other brain areas may be able to acquire and express learned behaviors normally mediated in the amygdala, albeit less efficiently. Consistent with this idea, a number of studies have shown that, in tasks sensitive to amygdala lesions, the behavioral deficits are revealed quantitatively rather than qualitatively: the animals with lesions eventually show complete learning, and the deficits are revealed as the number of trials to criterion (Jones and Mishkin, 1972; Spiegler and Mishkin, 1981; Peinado-Manzano, 1987, 1988, 1989, 1990; Peinado-Manzano and Martinez-Martin, 1987). Alternatively, the incomplete elimination of the CPP might be due to the fact that the olfactory system redundantly gives rise to direct and indirect projections to almost all amygdaloid nuclei (de Olmos et al., 1985; Switzer et al., 1985). Due to this redundancy, the lateral nucleus-lesioned animals may have been able to identify the drug-paired compartment by odor-reward associations, while they were unable to identify the drug-paired visual and somatosensory stimuli, leading to the significant reduction of the CPP. In fact, we have observed that lesions of the lateral nucleus of the amygdala completely eliminated a food-produced CPP in which only visual cues were used (Hiroi et al., 1990).

The present study suggests that intrinsic neurons of the lateral nucleus of the amygdala mediate expression of the association of neutral stimuli and rewards. There is also evidence that the amygdala is involved in the mediation of certain effects of conditioned aversive stimuli on behavior (McGaugh, 1988). Large excitotoxic lesions of the amygdala impair passive avoidance (Dunn and Everitt, 1988; Cahill and McGaugh, 1990), and large electrolytic lesions centered in the central amygdaloid nucleus impair conditioned startle response (Hitchcock and Davis, 1986). A recent study showed that small electrolytic lesions of the lateral amygdaloid nucleus impaired the conditioned startle response (LeDoux et al., 1990). Further research will be required 
to determine the roles of different amygdaloid nuclei in mediating the effects of conditioned appetitive and aversive stimuli on behavior.

\section{References}

Agmo A, Berenfeld R (1990) Reinforcing properties of ejaculation in the male rat: role of opioids and dopamine. Behav Neurosci 104: $177-182$.

Bardo MT, Neisewander JL, Pierce RC (1989) Novelty-induced place preference behavior in rats: effects of opiate and dopaminergic drugs. Pharmacol Biochem Behav 32:683-690.

Beckstead RM (1979) An autoradiographic examination of cortical and subcortical projections of the mediodorsal projection (prefrontal) cortex in the rat. J Comp Neurol 184:43-62.

Ben-Ari Y, Zigmond RE, Moore KE (1975) Regional distribution of tyrosine hydroxylase, norepinephrine and dopamine within the amygdaloid complex of the rat. Brain Res 87:96-101.

Cador M, Robbins TW, Everitt BJ (1989) Involvement of the amygdala in stimulus-reward associations: interaction with the ventral striatum. Neuroscience 30:77-86.

Cahill L, McGaugh JL (1990) Amygdaloid complex lesions differentially affect retention of tasks using appetitive and aversive reinforcement. Behav Neurosci 104:532-543.

Carr G, White NM (1983) Conditioned place preference from intraaccumbens but not intra-caudate amphetamine injections. Life Sci 33:2551-2557

Carr G, White NM (1986) Anatomical dissociation of amphetamine's rewarding and aversive effects: an intracranial microinjection study. Psychopharmacology 89:340-346.

Clarke PBS, White NM, Franklin KBJ (1990) 6-Hydroxydopamine lesions of the olfactory tubercle do not alter $(+)$-amphetamine-conditioned place preference. Behav Brain Res 36:185-188.

de Olmos J, Alheid GF, Beltramino CA (1985) Amygdala. In: The rat nervous system (Paxinos G, ed), pp 223-334. Orlando: Academic.

Dunn LT, Everitt BJ (1988) Double dissociations of the effects of amygdala and insular cortex lesions on conditioned taste aversion, passive avoidance, and neophobia in the rat using the excitotoxin ibotenic acid. Behav Neurosci 102:3-23.

Estes WK (1969) Reinforcement in human learning. In: Reinforcement and behavior (Tapp JT, ed), pp 63-95. New York: Academic.

Everitt BJ, Cador M, Robbins TW (1989) Interactions between the amygdala and ventral striatum in stimulus-reward associations: studies using a second-order schedule of sexual reinforcement. Neuroscience 30:63-75.

Gaffan EA, Gaffan D, Harrison S (1988) Disconnection of the amygdala from visual association cortex impairs visual reward-association learning in monkeys. J Neurosci 8:3144-3150.

Groenewegen HJ, Van Dijk CA (1984) Efferent projections of ventral pallidum in the rat as studied with the anterograde transport of $P h a-$ seolus vulgaris leucoagglutinin (PHA-L). Neurosci Lett [Supp] 18:S58.

Hearst E, Pribram KH (1964) Appetitive and aversive generalization gradients in amygdalectomized monkeys. J Comp Physiol Psychol 58:296-298.

Heimer L, Wilson RD (1975) The subcortical projections of the allocortex: similarities in the neural associations of the hippocampus, the piriform cortex and the neocortex. In: Golgi centennial symposium (Santini M, ed), pp 177-193. New York: Raven.

Hiroi N, White NM (1989) Effects of dopamine antagonists on acquisition and expression of the amphetamine conditioned place preference. Soc Neurosci Abstr 15:1065.

Hiroi N, White NM (1990) The reserpine-sensitive dopamine pool mediates $(+)$-amphetamine conditioned reward in the place preference paradigm. Brain Res 510:33-42.

Hiroi N, McDonald RJ, White NM (1990) Involvement of the lateral nucleus of the amygdala in amphetamine and food conditioned place preferences. Soc Neurosci Abstr 16:605.

Hitchcock J, Davis M (1986) Lesions of the amygdala, but not of the cerebellum or red nucleus, block conditioned fear as measured with the potentiated startle paradigm. Behav Neurosci 100:11-22.

Jones B, Mishkin M (1972) Limbic lesions and the problem of stimulus-reinforcement associations. Exp Neurol 36:362-377.

Kelley AE, Domesick VP (1982) The distribution of the projection from the hippocampal formation to the nucleus accumbens in the rat: an anterograde and retrograde horseradish peroxidase study. Neuroscience $7: 2321-2335$.

Kelley AE, Domesick VB, Nauta WJH (1982) The amygdalostriate projection in the rat: an anatomical study by anterograde and retrograde tracing methods. Neuroscience 7:615-630.

Kluver H, Bucy PC (1937) "Psychic blindness" and other symptoms following bilateral temporal lobectomy in rhesus monkeys. Am J Physiol 119:352-353.

Kluver H, Bucy PC (1939) Preliminary analysis of functions of the temporal lobes in monkeys. Arch Neurol Psychiatry 42:979-1000.

Krayniak PE, Meibach RC, Siegel A (1981) A projection from the entorhinal cortex to the nucleus accumbens in the rat. Brain Res 209: $427-431$.

LeDoux JE, Cicchetti P, Xagoraris A, Romanski M (1990) The lateral amygdaloid nucleus: sensory interface of the amygdala in fear conditioning. J Neurosci 10:1062-1069.

Martin-Iverson MT, Ortmann F, Fibiger HC (1985) Place preference conditioning with methylphenidate and nomifesine. Brain Res 332: $59-67$.

Mayer ML, Westbrook GL (1987) Cellular mechanisms underlying excitotoxicity. Trends Neurosci 10:59-61.

McGaugh JL (1988) Modulation of memory storage processes. In: Memory - an interdisciplinary approach (Solomon PR, Goethals GR, Kelley CM, Stephens BR, ed), pp 33-66. New York: Springer.

Mehrara BJ, Baum MJ (1990) Naloxone distupts the expression but not acquisition by male rats of a conditioned place preference response for an oestrous female. Psychopharmacology 101:118-125.

Mithani S, Martin-Iverson MT, Phillips AG, Fibiger HC (1986) The effects of haloperidol on amphetamine-and methylphenidate-induced place preferences and locomotor activity. Psychopharmacology 90: 247-252.

Murray EA, Mishkin M (1985) Amygdalectomy impairs cross-modal association in monkeys. Science 228:604-605.

Nachman M, Ashe JH (1974) Effects of basolateral amygdala lesions on neophobia, learned taste aversion, and sodium appetite in rats. J Comp Physiol Psychol 87:622-643.

Nauta WJH, Smith GP, Faull RLM, Domesick VB (1978) Efferent connections and nigral afferents to the nucleus accumbens septi in the rat. Neuroscience 3:385-401.

Ottersen OP (1980) Afferent connections to the amygdaloid complex of the rat and cat: II. Afferents from the hypothalamus and the basal telencephalon. J Comp Neurol 194:267-289.

Ottersen OP (1981) The afferent connections of the amygdala of the rat as studied with retrograde transport of horseradish peroxidase. In: The amygdala complex (Ben-Ari Y, ed), pp 91-104. Amsterdam: North-Holland.

Parkinson JK, Murray EA, Mishkin M (1988) A selective mnemonic role for the hippocampus in monkeys: memory for the location of objects. J Neurosci 8:4159-4167.

Paxinos G, Watson C (1982) The rat brain. New York: Academic.

Peinado-Manzano A (1987) Role of the lateral nucleus of the amygdala in successive conditional visual discrimination learning in rats. Med Sci Res 15:383-384.

Peinado-Manzano A (1988) Effects of bilateral lesions of the central and lateral amygdala on free operant successive discrimination. Behav Brain Res 29:61-72.

Peinado-Manzano A (1989) Intervention of the lateral and central amygdala on the association of visual stimuli with different magnitude of reinforcement. Behav Brain Res 32:289-296.

Peinado-Manzano A (1990) The role of the amygdala and the hippocampus in working memory for spatial and non-spatial information. Behav Brain Res 38:117-134.

Peinado-Manzano A, Martinez-Martin A (1987) Effects of basolateral amygdala lesions in the retention of a visual discrimination in rats. Med Sci Res 15:801-802.

Phillipson OT, Griffiths AC (1985) The topographic order of inputs to nucleus accumbens in the rat. Neuroscience 16:275-297.

Raisman G, Cowan WM, Powell TPS (1966) An experimental analysis of the efferent projection of the hippocampus. Brain 89:83-101.

Reicher MA, Holman EW (1977) Location preference and flavor aversion reinforced by amphetamine in rats. Anim Learn Behav 5:343346.

Rolls ET, Rolls BJ (1973) Altered food preferences after lesions in the basolateral region of the amygdala. J Comp Physiol Psychol 83:248259. 
Schreiner L, Kling A (1953) The behavioral changes following rhinencephalon injury in cat. J Neurophysiol 16:643-659.

Schreiner L, Kling A (1956) Rhinencephalon and behavior. Am J Physiol 184:486-490.

Scoles MT, Siegel S (1986) A potential role of saline trials in morphineinduced place-preference conditioning. Pharmacol Biochem Behav 25:1169-1173.

Sherman JE, Roberts T, Roskam SE, Holman EW (1980) Temporal properties of the rewarding and aversive effects of amphetamine in rats. Pharmacol Biochem Behav 13:597-599.

Siegel A, Edinger H, Ohgami S (1974) The topographical organization of the hippocampal projection to the septal area: a comparative neuroanatomical analysis in the gerbil, rat, rabbit and cat. J Comp Neurol 157:359-378.

Sorensen KE, Witter MP (1983) Entorhinal efferents reach the caudate-putamen. Neurosci Lett 35:259-364.

Spiegler BJ, Mishkin M (1981) Evidence for the sequential participation of inferior temporal cortex and amygdala in the acquisition of stimulus reward associations. Behav Brain Res 3:303-317.

Spyraki C, Fibiger HC, Phillips AG (1982a) Attenuation by haloperidol of place preference conditioning using food reinforcement. Psychopharmacology 77:379-382.

Spyraki C, Fibiger HC, Phillips AG (1982b) Dopaminergic substrates of amphetamine-induced place preference conditioning. Brain Res 253:185-193.

Sutherland RJ, McDonald RJ (1990) Hippocampus, amygdala and memory deficits in rats. Behav Brain Res 37:57-59.
Swanson LW, Cowan WM (1975) A note on the connections and development of the nucleus accumbens. Brain Res 92:324-330.

Swanson LW, Cowan WM (1977) An autoradiographic study of the organization of the efferent connections of the hippocampal formation in the rat. J Comp Neurol 172:49-84.

Swerdlow NR, Koob GF (1984) Restrained rats learn amphetamineconditioned locomotion, but not place preference. Psychopharmacology 84:163-166.

Switzer RC, de Olmos J, Heimer L (1985) Olfactory system. In: The rat nervous system (Paxinos G, ed), pp 1-36. Orlando: Academic.

Totterdell S, Smith AD (1989) Convergence of hippocampal and dopaminergic input onto identified neurons in the nucleus accumbens of the rat. J Chem Neuroanat 2:285-298.

Turner BH (1981) The cortical sequence and terminal distribution of sensory related afferents to the amygdala complex of the rat and monkey. In: The amygdala complex (Ben-Ari Y, ed), pp 51-62. Amsterdam: North-Holland.

Turner BH, Zimmer J (1984) The architecture and some of the interconnections of the rat's amygdala and lateral periallocortex. J Comp Neurol 227:540-557.

Williams DJ, Crossman AR, Slater P (1977) The efferent projections of the nucleus accumbens in the rat. Brain Res 130:217-227.

Zola-Morgan S, Squire LR, Amaral DG (1989) Lesions of the amygdala that spare adjacent cortical regions do not impair memory or exacerbate the impairment following lesions of the hippocampal formation. J Neurosci 9:1922-1936. 